\title{
Exploration of creative talents training mode of clothing and costume design specialty in the new era
}

\author{
Liu Jianjun \\ Minnan Science and Technology Institute, Fujian Normal University, Fujian 362332, China
}

Keywords: fashion and dress design specialty; new period; professional creative talents; training mode; research and analysis

\begin{abstract}
With the development and progress of the society, our residents' living concept and living standards have been greatly improved, the need for life in the clothing and apparel have new requirements and pursuit, gradually changing to the aesthetic direction. With the China's colleges and universities gradually began to set up the corresponding professional clothing and apparel design, the profession itself has strong practical and practical, have a certain quality of life to meet the requirements of China's residents. In the new period, the students of clothing and costume design should not only have the theories that should be possessed of the specialty of costume design, but also should have certain practical abilities. Mainly refers to the new period of college students in the social needs and training, should learn and practice actively, the clothing and apparel design specialty in China should also according to the needs of society and culture with pertinence, orientation, teaching should be scientific and reasonable teaching methods, effective to improve the quality of teaching in Colleges and universities of professional clothing and apparel design, so as to cultivate useful talents for the society.
\end{abstract}

\section{Introduction}

With the development of the times and social progress, our country's overall economic level has been greatly improved, the level of economic and social status in the whole world with some improvement, modern structure of social life but also there have been some changes. In our country's clothing industry structure, the performance is very prominent, appeared the multiplex situation, has the certain rudiment to the clothing profession classification and the profession division. And, because of the improvement of our country's standard of living, the requirements for clothing have also put forward higher requirements. Therefore, China's garment industry workers in the work process, besides should have a certain professional knowledge, but also have the ability to use the development and changes of the society, the most important is the ability to innovate. So, with clothing and apparel design professional colleges and universities should pay attention to the training of professional talents of our country in the process of the corresponding theory, school education, but also should be able to take into account the needs of society in the new period at this stage, so it can be more targeted and more accurate cultivate talents for social needs. And more innovative talents[1].

\section{Talent training mode in Colleges and universities in the new era}

At the present stage in our country, most colleges and universities in the new period, specified by the appropriate personnel training mode mainly refers to and the current stage of the theory of modern education and ideological education must be combined, and according to the training objectives of the society in the new period and education requirements into consideration, to construct a complete set of curriculum system and teaching the content, and to formulate the corresponding professional assessment system and the corresponding management exercises, and ensure to improve the talent education to a certain extent, and make certain the training objectives and curriculum design and teaching process of the corresponding. In general, models should have a 
comprehensive training stage in the new period of innovation of professional clothing and apparel design talent, and to cultivate applied talents and innovative talents mode, can be more effective for our country's garment industry to ensure its service, can effectively improve the. And talent training model in higher school in our country should present garment enterprises and to combine, so as to formulate the corresponding training mode of construction, culture and combined with the changes of stages in the development of the times and talent. To a certain extent, it can adjust the training mode of talents effectively. At present, due to China's clothing and clothing design driven in the world continuously enhanced, for the cultivation of talent in the industry of our country also put forward higher requirements, in this environment, we should reform the innovation type of the whole university clothing and clothing design, the establishment of a meet the overall social environment in our country, and can effectively cultivate the new mode of cultivating comprehensive talents for the society of the garment industry[2].

\section{The present situation of the personnel training mode of costume and costume design specialty in Colleges and universities in China}

What is needed in our society is not only the talent should have appropriate clothing and apparel design professional knowledge talents, it also should have comprehensive knowledge ability and innovation ability, and to make sure the people involved in the clothing and apparel design activities before. However, due to the present stage of our country many colleges and universities cultivate clothing and clothing design talent, only to learn professional knowledge of fashion design, does not have the corresponding ability innovation ability and comprehensive application. And, in our country for the cultivation of professional talent, although to the personnel training goal of development, but the clothing design has not yet been combined with the quality standard of talent, also will not be able to show the talent standard. The talents needed in the clothing industry should be able to match the talents needed by the garment enterprises at the present stage, and have higher ability to apply clothing. In recent years, due to the improvement of living standards and speed up the pace, a lot of knowledge and ideas to update speed continues to increase, and when the time for students to graduate, although with some professional theories, the practice ability and comprehensive application ability is poor but are not able to adapt to the fast pace of change at this stage the social environment, at work there will be some problems. At present, our country for the clothing design and clothing design comprehensive talent needs, but many of the graduate students can not find work, the main reason is because the clothing design at this stage of our country colleges and universities in the talent training plan there is a lag and is not reasonable, not to follow the development the change of social reform and their teaching mode[3].

In the teaching of colleges and universities, only pay attention to theoretical teaching, ignore practice teaching, is basically a common problem of each comprehensive specialty, and in the new period of clothing and clothing design professionals in the training of more serious. In the process of personnel training in Colleges and universities, mainly through some school teaching activities, let professional fashion design students can learn basic knowledge in fashion design and master the relevant, but very little for the clothing design practice is the lack of teaching to cultivate students' innovation ability in a certain behavior the extent of the. The main reason for these phenomena may be that our country attaches great importance to classroom teaching, the traditional teaching thinking is more stubborn, only to adopt a single teaching mode for teaching. In order to better complete their teaching plan and activities, teachers in higher education institutions can not be serious and complete in teaching methods such as experimental teaching and case teaching. In addition, the examination of higher school the corresponding behavior is very backward, just a simple theoretical knowledge about the investigation, and to study the practical ability of students in almost no time to memorize and recite the theoretical knowledge but also waste a lot of time, these are in a certain extent restricts the students practical ability upgrade[4].

The study found that the program through professional clothing and apparel design for most of our higher school personnel training system, training a lot of talent there are some problems in the professional training course accounts for a large proportion, and opened in the theoretical courses in 
the professional course is too detailed and professional elective course, no good curriculum is divided according to the age, and the existence of overlapping problem certain specialized knowledge. In addition, teachers in higher education institutions pay more attention to the teaching of their own experience instead of developing their own creativity and creativity. Such talent training model can not meet the needs of professionals in the new era of society, and there is no way to meet the changing clothing market environment.

\section{New period clothing and clothing design specialty innovation talented person raise pattern}

Our higher education is to impart knowledge, improve students' learning ability and the ability to work place, with our traditional education idea and core content, higher school teachers as a leader in the classroom teaching, the main teaching mode should be in the classroom teaching. The school to cultivate innovative society that can meet the need of talent, should be on the students' innovation consciousness and innovation ability training and improve the good, to improve the training and give students more personalized and oriented. High school classroom in the school should be the basic theory, the present lag of teaching theory and teaching ideas are clear, the students' thinking ability changes, the students basic quality of professional fashion design, should not only in the theoretical basis of the ability of knowledge, but should be combined with the garment design the cultivation of comprehensive ability. Our country high school teachers should fully design in teaching practice teaching, cultivating students' practical ability, and the ability of space imagination, the thinking of students to design, train students' innovation consciousness in fashion design[5].

The team of teachers of higher education quality and level directly determines the teaching quality and teaching effect of luxury, and can further determine our society within the scope of clothing design and clothing design level. Teacher's teaching ability and teaching means can also determine the training effect of innovative talents to a certain extent. Therefore, colleges and universities of our country should take some measures to enhance the overall quality of the professional clothing and clothing design in the school team of teachers, improve their comprehensive application ability and professional practice ability. First, the school should carry on teachers to cultivate the innovation ability, eliminate backward teachers teaching thoughts, change rigid teaching mode of thinking, training and exercise with innovative consciousness and thinking ability of the teachers, the only way to the students' creative thinking and consciousness of culture and influence. If the teachers' ideas are backward, the trained students will not have a good sense of innovation and comprehensive ability. So, the school should encourage teachers to complete the corresponding theory of classroom teaching, and to a certain extent into the internal industry and garment enterprises to carry out investigation and study, for use at the present stage the enterprise innovation technology and means of learning, can also and other related researchers and garment industry research and analysis, and effective and the students ability and combined with the actual situation, finally back to the classroom. Second, some training in teaching mode adopted in school teachers, for the clothing and clothing design professional teachers, should not only give students teaching theoretical knowledge, we should pay more attention to the teacher's business is to be required, to ensure the professional teachers in the field of clothing, have the knowledge and, to constantly reflect on the process of teaching, and cultivate professional talents, to carry out innovative teaching jelly. Third, schools should cultivate teachers' scientific research ability. Through regular clothing education for teachers, teachers' professional level will be raised. And to ensure that teachers can adapt to the international environment and modernization, to ensure the practice teachers can have a front garment, and to carry out technical clothing to practice ability of students in the teaching process of teaching.

Whether the school teaching method is proper or not can also train the students' innovative practice ability to a certain extent. In the teaching activities of clothing and costume design specialty in Institutions of higher learning in China, it is important to put forward the importance of innovative teaching methods. And in the process of teaching practice, will be designed to show clothing and clothing for students to watch. The content of the design for students is not set, so that students can carry out independent thinking and thinking ability training. Let students learn to 
analyze the content of learning from different angles, and improve the corresponding teaching methods and programs. First, teaching can be used to group discussions, through the guidance of teachers, students are discussed, and fully mobilize the enthusiasm of the students' creative thinking and learning, allowing students to practice in the course, not in accordance with the given model and framework of teacher learning, but to imagine, design and fabrication of its own the. In such a teaching mode, the teacher is only in a guiding and enlightening role. Teachers in order to realize this teaching mode better, should be combined with the corresponding teaching work, to encourage schools to carry out a variety of teaching and research projects, encourage the students to participate in the project, in order to improve the students' practical ability[6].

The school curriculum system is perfect or not can directly affect the students' knowledge structure, learning process of professional knowledge in school students, should be based on students to enhance the professional training and be able to carry on the system of discipline. In the process of professional training, to improve students' learning ability, expand the students' professional vision, and ensure that students can have certain creative thinking ability, and promote their overall development.

\section{Conclusion}

To sum up, the talents of fashion and costume design specialty should be innovative and practical in the new period, and can meet the requirements of garment enterprises in society. The traditional teaching mode of clothing and fashion design gradually has some problems, which is not only harmful to students' learning, but also has a great influence on the development of students' creative ability. Therefore, according to the above reasons, it is necessary to reform the training mode of creative talents in the new era of clothing and clothing design from the following aspects. First, change the teaching mode and concept of higher education. Second, the construction of high-quality teachers team. Third, improve the school teaching methods. Fourth, the school should improve the corresponding curriculum system. Believe that through research and analysis of the new period, to the future of clothing and clothing design professionals to help innovative talent training model to explore, cultivate more innovative ability and innovative thinking of the clothing talent, further promote the talents of practical ability, serve our country's garment industry.

\section{References}

[1]Wang J. On the Environmental Art Design Talents Training Mode in New-era Institutions of Higher Learning[J]. Journal of Hefei University, 2013.

[2]Huang L, Gong P, Zhang J. The Reform of the Practice Teaching and the Training Mode of Creative Talents for Electronic-Information-Type Specialties[M]// Advances in Computer Science, Environment, Ecoinformatics, and Education. Springer Berlin Heidelberg, 2011:205-210.

[3]Guo Z, Junshan G E. Exploration on Promoting the Productive Training Base Construction in Higher Vocational Colleges in the New Era[J]. Journal of Guangdong Industry Technical College, 2016.

[4]Yan W U. On Cultivating Creative Thinking of Architectural Talents in the New Era[J]. Journal of Guangdong University of Technology, 2009.

[5]Zhan W F. Exploration of training mode of"one-majored-multipotent"design talents[J]. Journal of Jiamusi Education Institute, 2011.

[6]Zhang Q. Teaching Reform of Costume Design Specialty[J]. Journal of Shandong Institute of Commerce \& Technology, 2006. 